\title{
Reforestation by Seedlings and Saplings: Challenges and Solutions
}

\author{
Shegelman I. R. ${ }^{1 *}$, Vasilev A. S. ${ }^{2}$, Lukashevich V. M. ${ }^{2}$, Sukhanov Y. V. ${ }^{2}$, Galaktionov O. N. ${ }^{3}$, \\ Kuznetsov A. V. ${ }^{3}$, Krupko A. M. ${ }^{4}$ \\ ${ }^{1}$ Doctor of Technical Sciences, Professor, Cross-cutting technology and economic security, Petrozavodsk State University (PSU), 33, Lenina pr., \\ 185910, Petrozavodsk, Republic of Karelia, Russia \\ ${ }^{2}$ Candidate of Technical Sciences, Associate Professor, Technologies and organizations of the forest complex, Petrozavodsk State University (PSU), 33, \\ Lenina pr., 185910, Petrozavodsk, Republic of Karelia, Russia \\ ${ }^{3}$ Doctor of Technical Sciences, Associate Professor, Technologies and organizations of the forest complex, Petrozavodsk State University (PSU), 33, \\ Lenina pr., 185910, Petrozavodsk, Republic of Karelia, Russia \\ ${ }^{4}$ Candidate of Technical Sciences, Associate Professor, Mathematical Analysis, Petrozavodsk State University (PSU), 33, Lenina pr., 185910, \\ Petrozavodsk, Republic of Karelia, Russia
}

Received: 18/06/2020

Accepted: 18/09/2020

Published: 20/12/2020

\begin{abstract}
Despite the urgent need to accelerate the development of intensive forest management and reforestation technologies in Russia, the problem of creating progressive technologies and techniques to increase the efficiency of reforestation by seedlings and saplings of forest crops has not been completely resolved, which are serious challenges for accelerated and high-quality reforestation. Of particular concern is the lack of patented equipment competitive in the domestic and foreign markets for reforestation by seedlings and saplings of forest crops that can accelerate the creation of highly productive forests. To answer these challenges, it is proposed as a tool for the synthesis of patentable solutions that increase the efficiency of forest regeneration by seedlings and saplings of forest crops, to use the knowledge base formed on the basis of patent information search and the author's methodology of functional, structural and technological analysis. A classification of the main areas of patenting in this area is proposed. The most characteristic patented objects of technologies and equipment that can be used as analogues and prototypes for the synthesis and patenting of new intellectual property for planting seedlings/saplings, as well as business entities patenting in this area, are identified. The effects (goals) for the achievement of which the technical solutions incorporated in the patents are directed are revealed. Using the generated knowledge base and the FSTA methodology, a synthesis of new patentable technical solutions has been carried out. Its features and some results are given on the example of several basic objects of machines and manual devices for planting seedlings/saplings. It is proved that the application of the proposed methodology to the selected object for improving the processes of planting seedlings/saplings is effective, which is confirmed by the development and patenting of fundamentally new technical solutions for equipping forest regeneration with seedlings and saplings of forest crops.
\end{abstract}

Keywords: Forest regeneration, Forest crops, Seedling, Sapling, Patent, Synthesis of patentable solutions, Functional, Structural and technological analysis

\section{Introduction}

An analysis of the state of the forest complex of the Russian Federation shows that as a result of a long period of extensive exploitation of the forests of the timber industrial regions of Russia (Arkhangelsk, Irkutsk, Kirov regions, the Republic of Komi, the Republic of Karelia, etc.), the potential of the country's colossal forest resources is used inefficiently. Despite the serious scientific backlog of researchers on technologies and techniques for reforestation, the problem of creating progressive technologies and techniques to improve the efficiency of reforestation by seedlings and saplings of forest crops has not been completely resolved. Different technologies and equipment have their own certain not only advantages, but also disadvantages, the qualitative elimination of which requires spasmodic technological and technical solutions. One of the most important factors confirming the

Corresponding author: Shegelman I. R., Doctor of Technical Sciences, Professor, Cross-cutting technology and economic security, Petrozavodsk State University (PSU), 33, Lenina pr., 185910, Petrozavodsk, Republic of Karelia, Russia. E-mail: education.com.ru@gmail.com level of such decisions is the patenting by researchers and developers of the results of their intellectual property. It can be stated that the lack of efficiency in the creation and intensive implementation of advanced technologies and equipment in Russia to increase the efficiency of forest regeneration by seedlings and saplings of forest crops are serious challenges for the formulation and implementation of strategies for forestry regions aimed at solving the problems of intensive forest management with accelerated and highquality restoration of Russian forests. Of particular concern is the lack of patented technology that is competitive in the domestic and foreign markets for reforestation by seedlings and saplings of forest crops. Therefore, the reason is that developers and inventors must take into account the fact that different technologies and equipment have their own specific advantages, as well as serious shortcomings that impede the realization of the scientific and technological potential inherent in the design. The answer to these challenges is the qualitative elimination of these shortcomings, which requires developers and inventors of spasmodic technological and technical solutions in the field of forest restoration by seedlings/saplings. All this necessitates the search for an 
effective methodology to solve the problem of synthesizing patentable solutions that increase the efficiency of forest regeneration by seedlings and saplings of forest crops. In this regard, the authors are tasked with proving that such a methodology may be a methodology for forming a patentinformation search and using a knowledge base in combination with the author's methodology of functionalstructural-technological analysis.

\section{Literature Review}

The Russian Federation has enormous forest resources, but is inferior to a number of foreign countries (Finland, Sweden, and Canada) in the field of indicators characterizing rational forest management. This situation has been aggravated by long-term logging based on extensive forest exploitation in multi-forest regions of the country $[1,2]$. In this regard, scientific research in the field of forest cultivation has been intensified in the country [3-7], forest seed development [8], forest genetics and selection [9]. An important place among these works is occupied in the field of creating forest crops [10-12], aimed at creating artificial forest crops for the formation of forests with increased productivity and rational commodity structure of stands. The issues of mechanization of reforestation works, including planting of forest cultures, are rather widely considered in Asmolovsky M.K., Bartenev I.M. and Yudin R.V., Dornyak O.R., Drapalyuk M.V., Kazakov I.V. and Orudzhov E.S., Druchinin D.Yu. and Drapalyuk M.V., Popikov P.I., Sungurova N.R., Titov P.I., Shavkov M.V. [13-20].

Many publications describe machines for planting seedlings/saplings in forestry machines equipped with support wheels, a towing device, a coulter, seeding tools, a seat for the planter and a capacity for seedlings, as well as manual and mechanized hole-forming machines (the term "often refers to digger") for the preparation of planting pits and for planting large seedlings in clearings, green areas, when laying nurseries [21]. The latter, based on the principle of operation, are based on penetration into the ground by impact or drilling. An analysis of the state of the forest complex of the Russian Federation shows that, as a result of a long period of extensive exploitation of the forests of the timber industry regions of Russia (Arkhangelsk, Irkutsk, Kirov regions, Komi Republic, the Republic of Karelia, etc.), the potential of the country's colossal forest resources is used inefficiently. This is confirmed by the data on the development of the forest complex of Russia until 2030, approved by the Government of Russia on 20.09.2018, on low removals of wood per unit area of production forests, on insufficient forest restoration efficiency, high loss of forest crops, and the process of replacing conifers with deciduous trees. The share of areas restored by forest crops is significantly lower than in foreign countries. Russian scientists conducted serious long-term scientific research on the problem under consideration. However, it can be stated that despite the serious scientific backlog of researchers on technologies and techniques for reforestation, the problem of creating advanced technologies and techniques for improving the efficiency of forest regeneration by seedlings and saplings of forest crops has not been completely resolved.

Of particular concern is the lack of patented equipment for forest regeneration by seedlings and saplings of forest crops, which is competitive in the domestic and foreign markets. Serious losses occurred during the perestroika period when sectoral forest science was seriously destroyed in Russia and Russian forestry engineering suffered serious losses. For researchers, developers and inventors of advanced forest technologies and equipment, including as shown below, for forest restoration with large planting material (seedlings/saplings), this situation is a serious challenge. A challenge is that developers and inventors must take into account the fact that various technologies and equipment have their own specific advantages, as well as serious disadvantages that impede the realization of the scientific and technical potential inherent in the design. High-quality elimination of deficiencies requires step-by-step technological and technical solutions in the field of forest restoration by seedlings/saplings from developers and inventors. It seems to us that one of the most important factors confirming the level of such decisions is the patenting by researchers and developers of the results of their intellectual property. In this regard, based on research in the field of analysis and synthesis of patent-capable objects of engineering and technology [22, 23], we put forward the hypothesis that the tool for solving the synthesis of patentable solutions that increase the efficiency of forest regeneration by seedlings and saplings of forest crops can be the formation on the basis of patent information search and the use of a knowledge base, as well as an author's methodology technological analysis.

\section{Materials and Methods}

In carrying out this work, technologies and equipment for reforestation of seedlings and saplings of forest crops were considered as objects for the analysis and synthesis of new solutions. The following abbreviations are used in this work:

- Voronezh State Forestry Engineering Academy - VSFEA;

- Voronezh State University-VSU;

- All-Russian Scientific Research Agroforestry Institute ARSRAI;

- All-Russian Research Institute of Forestry and Forestry Mechanization-ARRIFFM;

- Irkutsk State Transport University - ISTU;

- Karelian Scientific Center of the Russian Academy of Sciences - KSCRAS;

- Michurinsky State Agrarian University - MSAU;

- Moscow State Forest University - MSFU;

- Petrozavodsk State University - PetrSU;

- Volga State Technological University - VSAA:

- Primorsky State Agricultural Academy - PSAA;

- Creative innovative enterprise "Novator" - CIE "Novator";

- Pacific State University - PSU;

- Federal Scientific Center for Agroecology, Integrated Land Reclamation, and Protective Afforestation - Federal Scientific Center AILRPA.

According to the methodology of work, the task was set of sequentially performing the following stages of work:

1. Collection and analysis of information in the field of the state of the problem in the field of creation of technologies and equipment for forest regeneration by seedlings and saplings of forest crops. As materials at this stage of the work, published materials of Russian scientists were used, which are contained in articles, materials of dissertation research, monographs.

Particular attention was paid to the analysis of materials contained in the dissertations of Russian scientists:

- Bobushkina S.V. [10]. The intensity of growth and development of pine seedlings with a closed root system under different growing conditions for reforestation in the Arkhangelsk region;

- Boyko T.A. [3]. Features of mycorrhiza formation and growth of coniferous seedlings in forest nurseries of the Perm Territory; 
- Gavrilova O.I. [11]. Reforestation and coniferous forest productivity of the Republic of Karelia;

- Popikov P.I. [17]. Work processes of forestry machines with hydraulic drive;

- Posmetiev V.I. [24]. Fundamentals of improving the protection of forest soil-processing implements from overloads;

- Sokolov A.I. [12]. Ecological and silvicultural basics of creating forest crops on unforested felling with littered soils of the Northwest taiga zone;

- Sungurova N.R. [18]. Theory and practice of artificial reforestation in the north of the Russian Plain;

- $\quad$ Titov P.I. [19]. Improving the technological process and the design of a forest planting machine for nurseries;

- Shavkov M.V. [20]. Justification of the parameters of the combined opener of the planting machine.

The analysis showed that in spite of a serious scientific foundation in the studied area, the work of scientists is often exploratory in nature and is carried out without close interaction with the enterprises of forestry engineering. In this regard, the accelerated creation of innovative technologies based on patentable solutions is required for the effective regeneration of forests by seedlings and saplings of forest crops for their subsequent commercialization together with industrial partners.

2. The hypothesis that the synthesis of effective patentable solutions that increase the efficiency of forest regeneration by seedlings and saplings can be the formation and use of the knowledge base and the author's methodology of functionalstructural-technological analysis "FSTA".

3. Formation of the knowledge base in the field using the patent information fund of the Federal Institute of Industrial Property (FIIP).

4. The selection of specific basic objects (analogues and prototypes) that require improvement using the FSTA methodology;

5. Synthesis using the generated knowledge base and the FSTA methodology of new technical solutions.

When implementing the "FSTA" methodology, information is structured and carefully studied regarding the basic facility, in relation to which it is planned to find a new technical solution for its improvement. At the same time, they are thoroughly comprehensively studied and the closest analogues and prototypes identified.

Based on the functional analysis of "FA", the functions realized by the basic object and the possibilities of their development, supplementing with new functions, combining and diluting functions in space and time are studied.

Using the structural analysis "STA", the structure of the base object in combination with all its elements is studied; using the technological analysis "TA", all operations performed by the basic and related equipment objects and their elements are carefully studied. These subtypes of analysis are recommended to be performed using the "brainstorming" method.

6. Isolation by the method of expert evaluation of the best of the generated solutions and their patenting.

Patent registration of research results was promoted by many years of inventive experience of the authors of this work [22, 23].

\section{Results and Discussion}

When forming the knowledge base using the patent information fund, Russian patents for inventions and utility models were grouped as follows.

Patents aimed at improving the planting processes of seedlings/saplings of forest crops with the continuous movement of forest machines. VSFEA has patented a machine for planting seedlings with a closed root system [25], which includes a frame, hoppers for charged and used cassettes, support wheels, compacting rollers, a coulter, and a seedling feeding mechanism. The achieved effect of using the patented design is to increase the reliability, planting quality and survival rate of forest crops. Another patented VSFEA design [26] is intended for planting seedlings/saplings on ravinebeam and mountain slopes. The achieved effect is the exclusion of removal of the upper fertile soil layer from the planting zone of seedlings/saplings, improving the quality of planting and improving working conditions of planters. VSU also patented a machine [27] for planting seedlings with a closed root system. The achieved effect is the provision of high-quality planting of seedlings/saplings with a closed root system. The design features of the forest planting machine, patented by the Federal Research Center AILKPA [28], are aimed at simplifying its design, reducing traction resistance and increasing the survival rate of seedlings. Pacific State University has patented a planting machine seeding tool [29], which improves the quality of planting root roots and increases labor productivity. The patented design of the machine [30] by ARRIFFM ensures an increase in the quality of planting seedlings with a closed root system, simplifies the design of the machine, improves its performance and performance when working on cuttings. A similar effect can be achieved by another ARRIFFM patented machine [31] by providing the necessary planting depth, the required degree of root fixation during operation, simplifying the design of the machine, increasing its reliability, operability and quality of landing on fresh felling. Among the machines of this class, one can distinguish a technical solution patented by ARSRAI on a machine for planting seedlings/saplings of tree and shrub species with enhanced functionality [32]. Thanks to new features, this machine performs additional technological operations during planting, introducing a hydrogel through the cavity in the coulter to the root system of seedlings/saplings and a binder liquid on the soil surface. The achieved effect is an increase in the survival rate of seedlings/saplings, ensuring their accelerated growth in severe climatic conditions of arid regions.

Patents aimed at improving the planting mechanisms of machines for planting seedlings and saplings. The patent of CIE "Novator" RUS No. 174663 [33] belongs to this class; provides high-quality planting of seedlings and saplings of tree species with closed and open root systems by maintaining the integrity of the closure-root of the coma of the plant.

Patents aimed at ensuring the spot planting of seedlings in areas inaccessible to ground means of mechanization and humans from the air. This class includes the VSFEA patent [34], in which the formation of capsules with forest reproductive material of a certain aerodynamic shape, weight and strength, with the necessary supply of nutrient, fungicidal and anti-predatory substances and their discharge from the air using unmanned aerial vehicles Helicopter, airplane or hybrid devices. The achieved effect is the provision of reforestation in the forest areas inaccessible to land means of mechanization and man.

Patents aimed at improving the processes of cyclic planting of seedlings using a trolley, including boxes with seedlings and a hole former, in which seedlings are planted. 
This class includes a series of patents of the VSU. The effects achieved in this case: according to the patent [35] - increase in productivity due to the reduction of time for planting the seedling and the number of workers employed on the toe of seedlings; according to patent [36] - improving the quality of planting seedlings, reducing the physical strength of the worker for forming holes, increasing the productivity of his labor; according to the patent [37]- improving the quality of work and productivity of the preparation of holes; according to the patent [36] - reduction of the physical strength of the worker during the formation of holes increasing the productivity of his labor.

Patents aimed at using the physical effects that affect forest seeds to accelerate the growth of seedlings. This class includes patents of the Institute of Plant Physiology named after K.A. Timiryazeva [38], aimed at obtaining high-quality seedlings with a large mass, developed root system and aerial parts in a shorter time; Voronezh State University patent [39], which increases the germination energy and seed germination after prolonged dry storage to obtain seedlings of high viability; patent of LLC "Siledia" [40], accelerating and increasing the percentage of germination, seed germination energy and the speed of obtaining planting material; patent of Karelian Research Center of the Russian Academy of Sciences [41], which increases the germination of pine seeds, germination energy, mass of seedlings and the diameter of the root neck.

Patents aimed at improving the processes of cutting the roots of seedlings and saplings of forest crops. This class includes patented VSFEA [42, 43] and ARRIFFM [44] technical solutions. The effect achieved through their use is to increase the efficiency and quality of pruning the roots of seedlings and saplings of forest crops with different root systems, and reduce labor costs for growing large-sized planting material without re-cultivation.

Patents aimed at improving the processes of planting seedlings using hand tools and mechanisms. Typical of this class of patents are the patent of the Training and Experienced Sabinsky Leskhoz [45], aimed at reducing the efforts of introducing the sword into the soil and creating a clear footprint, and the patent of the VSU [46], aimed at increasing productivity and quality of work when preparing holes for account for providing a fixed landing pitch.

Patents aimed at improving the processes of digging seedlings/saplings with a lump of soil in nurseries and under the forest canopy for subsequent transplantation. VSFEA has patented a machine for digging seedlings with a lump of soil [47], which provides improved quality and efficiency of digging planting material. MSAU No. 194500, [48] patented yet another machine for digging seedlings. The achieved effect is an improvement in the quality of work performed and a reduction in the energy consumption of seedlings excavation.

Patents aimed at improving the planting processes of seedlings of forest crops in the zone of radioactive contamination. The MSFU patent belongs to this class [49]. According to this method, seedlings are grown in a fertile substrate reinforced with a water-soluble film. The substrate is frozen, and seedlings with a closed root system are planted by dropping them from the aircraft into moist soil after snowmelt. The method provides for planting seedlings of conifers in the zone of radioactive contamination.

Patents aimed at developing machines that combine felling and planting seedlings. The patent of the Pacific State University [50] belongs to this class, the gripping-cutting device of which ensures the collapse of the stump parts in different directions, freeing up space for planting seedlings.
The achieved effect is an increase in productivity due to combining in one machine the operations of cutting trees and planting seedlings.

Patents aimed at improving the processes of formation of holes for planting seedlings/saplings of forest crops with a machine, followed by manual planting in the holes of seedlings/saplings. The PetrSU patent belongs to this class [51]. Work on the construction of this class of machines was begun in 1973 at the Leningrad Forestry Academy, then in PetrSU in the last century L-1, L-2, L-2U hole-forming machines were developed and manufactured, which later did not find application.

Patents aimed at preparing planting holes in a machine by drilling soil. The VSFEA patent [52] belongs to this class. The achieved effect is an increase in the quality of work, labor productivity, and a reduction in the time and material resources spent on preparing landing holes.

Patents aimed at improving reforestation processes using seedlings on mountain slopes. This class includes [53].

Thus, the analysis of the knowledge base allowed us to propose a classification of the main areas of patenting in this area, confirming it with some inventions and utility models patented in Russia. Among these areas:

- Improving the planting processes of seedlings/saplings of forest crops with the continuous movement of forest mashi;

- Improving the landing mechanisms of machines for planting seedlings and saplings;

- Ensuring the spot planting of seedlings in areas inaccessible to ground means of mechanization and man from the air;

- Improving the processes of cyclic planting of seedlings using a mobile trolley;

- Use of physical effects affecting forest seeds to accelerate the growth of seedlings;

- Improving the processes of cutting the roots of seedlings and saplings of forest crops;

- Improving the processes of planting seedlings using hand tools and mechanisms;

- Improving the processes of digging seedlings/saplings with a lump of soil in nurseries and under the forest canopy for subsequent transplantation;

- Improving the planting processes of seedlings of forest crops in the area of radioactive contamination;

- Development of machines combining tree felling and planting seedlings;

- Improvement of the processes of formation of holes for planting seedlings/saplings of forest crops by machine and manual planting;

- Preparation of planting holes by machine by drilling the soil;

- Improvement of reforestation processes using seedlings on mountain slopes.

- In the formation of the knowledge base, special attention was paid to the effects (goals) to achieve which the technical solutions incorporated in the patents are directed. We single out the main ones:

- Ensuring high quality planting of seedlings/saplings;

- Increase the survival rate of seedlings/saplings;

- Improving the quality of rooting seedlings/saplings;

- Ensuring the necessary landing depth and the required degree of incorporation of the root system;

- Exclusion of removal of the upper fertile soil layer from the planting zone of seedlings/saplings;

- Improving the working conditions of planting workers; 
- Simplification of structures and increasing the reliability of machinery and equipment for planting seedlings/saplings, increasing their operational performance when working on clearings;

- Expanding the functionality of machines and equipment for planting seedlings/saplings;

- Provision of reforestation in inaccessible to land means of mechanization and human forest areas;

- Increasing productivity by reducing the time for planting seedlings/saplings and the number of workers employed on the toe of seedlings;

- Increase in labor productivity, reduction of time and material resources;

- Ensuring the planting of seedlings/saplings in forest areas inaccessible to ground means of mechanization and man and in zones of radioactive contamination.

Using the above database, a synthesis of patentable technical solutions has been carried out. We give its features and some results.

Consider the goal of the synthesis of a new technical solution - to expand the functionality of a forest planting machine when working on felling areas for use in forestry, namely for planting large seedlings and saplings grown in the sowing department up to 3-4 years of age with root cutting, without manual setting fresh clearings without soil preparation. The closest in essence and taken as a prototype is a method of reforestation using a forest planting machine for planting seedlings and saplings on clearings. Description of the patent for the invention [54], including a frame made in the form of pivotally connected front and rear sections, support wheels, gap-cutter, opener and closing working bodies in the form of disks. This method includes moving the forest planting machine behind the base tractor, forming a landing gap in the ground with gap-cutter with a coulter, laying planting material in the planting gap, and sealing the root system of planting material with soil. The disadvantages of the known method were revealed: the complexity of its implementation and low productivity, since a shaft of vegetation (roots, fallen branches, grass, etc.) accumulates in front of the gap-cutter with the opener during the operation of the machine, which in turn requires periodic stopping of the machine and a time-consuming manual operation to remove the shaft formed before the crevice with the coulter from the vegetation, which impedes the movement of the machine and prevents the coulter from forming the furrow properly.

The concept of expanding the functionality of the forest planting machine while working on clear-cutting operations was based on the ideology that new functionality should provide increased productivity and ease of operation of the forest planting machine, which forms a planting gap in the soil with a slotted opener. At the same time, the option of increasing functional capabilities was chosen due to the fact that with the continuous movement of the base tractor of the forest planting machine, it is necessary to ensure the destruction of the shaft formed in front of it from vegetation (roots, fragments of boughs, fallen branches, grass, etc.) that is collected before the gap-cutter.

To implement the concept, when forming a landing slit, vegetation is simultaneously cut off above the earth's surface in front of the slit with a working body of a mul-black type with cutting elements. At the same time, the shaft from the vegetation that collects before the gap-cutter with the coulter is exposed to the cutting elements of the rotating working body, and they are crushed. Due to the fact that simultaneously with the formation of the landing slit, vegetation is cut off above the ground surface before the slit, and the vegetation that gathers before the slit with the coulter is affected by the cutting elements of the rotating working body, increasing the productivity and ease of operation of the forest the bottom machine, which forms a landing slot in the soil with gap-cutter with a coulter, due to the mechanization of the destruction of the shaft from the vegetation (roots, fallen branches, grass, etc.) collected before the slit.

For the synthesis of the new solution, one more basic object was chosen - the method of planting material landing by a machine, with a loading platform, a manipulator and a planting device. According to this method, a cutting machine forms landing holes and places seedlings/saplings in them. The synthesis goal was formulated - to increase productivity, reduce energy costs, negative impact on the soil when planting material. In the new method [55], a set of cassettes with planting devices is formed on the machine platform. After landing of planting material from one cassette, the manipulator places it on a platform or on the ground, then another is taken and the cycle repeats. An increase in work productivity and a reduction in energy consumption is achieved due to the fact that when forming a set of cassettes with planting material on the machine platform, the number of flights to the loading area for the next batch of planting material is reduced. Reducing the number of passes of the machine through the fibers reduces the negative impact on the soil. Since the cassettes with planting material are laid on the platform, for the implementation of the method and you can use logging machines with manipulators in the compressed period of forest planting.

As another basic option, the well-known device for manual planting of seedlings/saplings was selected, including a casing pipe open at the upper and lower ends, in the upper part of which there are mounted handles and a guide cone, in the lower part there is a foot stop and a fixed cheek, to which with the formation of a wedge-shaped knife, a rotary cheek with a pedal is attached. One of the options for this design was patented by the company Lännen tehtaat Oy [56]. Based on the analysis of the known construction, the goal was formulated - to ensure that the required distance between the planting holes and uniform distribution of holes for seedlings/saplings was maintained. In the modernized design, the hollow body is equipped with an indicator of the landing site, including a base with a mechanism for fixing it on the hollow body and a measuring scale for setting the seating standard, a laser direction indicator mounted on the base with the ability to change the vertical installation angle and equipped with a battery, and at least one hydro level for determining verticality. A patent was obtained for the developed design of PetrSU [57]. In addition to the said patent, the authors developed and patented 7 more technical solutions for hand tools for planting seedlings/saplings in the name of PetrSU (Russian patents No. 148183; No. 148208; No. 157494; No. 160520; No. 161354; No. 162811, No. 163771). Thus, the application of the proposed methodology to the selected object for improvement allowed the authors to develop and patent 10 new technical solutions for the equipment of forest regeneration by seedlings and saplings of forest crops.

\section{Conclusions}

An analysis of the state of the forest complex of the Russian Federation shows that, as a result of a long period of extensive exploitation of the forests of the timber industry regions of Russia (Arkhangelsk, Irkutsk, Kirov regions, Komi Republic, the Republic of Karelia, etc.), the potential of the country's colossal forest resources is used inefficiently. Russian scientists conducted serious long-term scientific research on this issue. Despite the serious scientific backlog of 
researchers of technologies and techniques for reforestation, the problem of creating progressive technologies and techniques to increase the efficiency of reforestation by seedlings and saplings of forest crops has not been finally resolved. Of particular concern is the lack of patented equipment for forest regeneration by seedlings and saplings of forest crops, which is competitive in the domestic and foreign markets. Serious losses occurred during the perestroika period when sectoral forest science was seriously destroyed in Russia and Russian forestry engineering suffered serious losses. For the creators of forest technologies and equipment, including for forest restoration with large-planting material (seedlings/saplings), this situation is a serious challenge. It is also a challenge that developers and inventors must take into account the fact that various technologies and equipment have their own certain advantages, as well as serious disadvantages that impede the realization of the scientific and technical potential inherent in the design. The answer to these challenges is the qualitative elimination of these shortcomings, which requires developers and inventors of spasmodic technological and technical solutions in the field of forest restoration by seedlings/saplings. It seems to us that one of the most important factors confirming the level of such decisions is the patenting by researchers and developers of the results of their intellectual property. In this regard, based on research in the field of analysis and synthesis of patentcapable objects of engineering and technology [22, 23], the authors hypothesized that the tool for solving the synthesis of patentable solutions that increase the efficiency of forest regeneration by seedlings and saplings of forest cultures can be the formation of a knowledge base and the author's methodology structural and technological analysis "FSTA". When implementing the "FSTA" methodology, information is structured and carefully studied in relation to the base facility, for which it is planned to find a new technical solution for its improvement. At the same time, they are thoroughly comprehensively studied and the closest analogues and prototypes identified. Based on the functional analysis "FA", the functions realized by the base object and the possibilities of their development, supplementing with new functions, combining and diluting functions in space and time are studied. Using structural analysis "STA", the structure of the base object in combination with all its elements is studied, using the technological analysis "TA", all operations performed by the basic and related objects of equipment and their elements are carefully studied. It is recommended that these subtypes of analysis be performed using the brainstorming method. In carrying out this work, technologies and equipment for reforestation of seedlings and saplings of forest crops were considered as objects for the analysis and synthesis of new solutions. According to the methodology of work, the task was set of sequentially performing the following stages of work: 1) Collection and analysis of information in the field of the state of the problem in the field of creating technologies and equipment for reforestation of seedlings and saplings of forest crops. As materials at this stage of the work, published materials of Russian scientists were used, which are contained in articles, materials of dissertation research, monographs. 2). The hypothesis that the synthesis of effective patentable solutions that increase the efficiency of reforestation by seedlings and saplings can be the formation and use of the knowledge base and the author's methodology of functional-structural-technological analysis "FSTA". 3) Formation of a knowledge base in the field under consideration using the FIPS Patent Information Fund. 4) The selection of specific basic objects (analogues and prototypes) that require improvement using the FSTA methodology. 5)
Synthesis using the generated knowledge base and the FSTA methodology of new technical solutions. 6) Isolation by the method of expert evaluation of the best generated solutions and their patenting. In the formation of the knowledge base, special attention was paid to identifying effects (goals) to achieve which the technical solutions incorporated in the patents are directed. The main ones were identified: ensuring high quality planting of seedlings/saplings; increase the survival rate of seedlings/saplings; improving the quality of embedding the roots of seedlings/saplings; providing the necessary depth of landing and the required degree of incorporation of the root system; the exception of the removal of the upper fertile soil layer from the planting zone of seedlings/saplings; improving working conditions for planting workers; simplification of structures and increasing the reliability of machines and equipment for planting seedlings/saplings, increasing their operational performance when working on clearings; expanding the functionality of machines and equipment for planting seedlings/saplings; provision of reforestation in forest areas inaccessible to land means of mechanization and man; increasing productivity by reducing the time for planting seedlings/saplings and the number of workers employed on the toe of seedlings; increase in labor productivity, reduction of time and material resources; ensuring planting of seedlings/saplings in forest areas inaccessible to ground means of mechanization and man and in zones of radioactive contamination. Based on the analysis of the knowledge base, a classification of the main areas of patenting was developed in the field of technologies and equipment for reforestation by seedlings and saplings of forest crops in this area: improvement of planting processes of seedlings/saplings of forest crops with continuous movement of forest mash; improving the landing mechanisms of machines for planting seedlings/saplings; ensuring the spot planting of seedlings in areas inaccessible to ground means of mechanization and human life from the air; improving the processes of cyclic planting of seedlings using a mobile trolley; the use of physical effects affecting forest seeds to accelerate the growth of seedlings; improving the processes of cutting the roots of seedlings and saplings of forest crops; improvement of the processes of planting seedlings using hand tools and mechanisms; improving the processes of digging seedlings/saplings with a lump of soil in the nursery and under the forest canopy for subsequent transplantation; improvement of the processes of planting seedlings of forest crops in the zone of radioactive contamination; development of machines combining tree felling and planting seedlings; improvement of the processes of the formation of holes for planting seedlings/saplings of forest crops by machine and manual planting in the holes of seedlings/saplings; preparation of planting holes by machine by drilling the soil; improvement of reforestation processes using seedlings on mountain slopes. During the formation of the knowledge base, the most characteristic patented technology and technology objects were identified that can be used as analogues and prototypes for the synthesis and patenting of new intellectual property objects for planting seedlings/saplings, as well as business entities conducting patenting in this area. Using the generated knowledge base and the FSTA methodology, a synthesis of new patentable technical solutions has been carried out. We give its features and some results on the example of several basic objects of machines and manual devices for planting seedlings/saplings. It is proved that the application of the proposed methodology to the selected object for improving the planting processes of seedlings/saplings is effective, which is confirmed by the development and patenting of 
fundamentally new technical solutions for the equipment of forest regeneration by seedlings and saplings of forest crops.

\section{Ethical issue}

Authors are aware of, and comply with, best practice in publication ethics specifically with regard to authorship (avoidance of guest authorship), dual submission, manipulation of figures, competing interests and compliance with policies on research ethics. Authors adhere to publication requirements that submitted work is original and has not been published elsewhere in any language.

\section{Competing interests}

The authors declare that there is no conflict of interest that would prejudice the impartiality of this scientific work.

\section{Authors' contribution}

All authors of this study have a complete contribution for data collection, data analyses and manuscript writing.

\section{References}

1. Babich NA. Reforestation in the European North (a synthesis of a hundred years of forest cultural experience). St. Petersburg. 1993.

2. Moiseev NA. Conditions for the transition from an extensive to an intensive model for the development of forest management and the forest sector of Russia. Bulletin of Moscow State Forest University. Forest Herald. 2014;3(18):11-17.

3. Boyko TA. Features of mycorrhiza formation and growth of coniferous seedlings in forest nurseries of the Perm Territory. 2006.

4. Gavrilova OI, Trishkin MN, Sokolov AI. The experience of reconstruction of leafy low-value young growth without tillage in the conditions of southern Karelia. Uchenye Zapiski Petrozavodsk State University. 2008;2(92):75-78.

5. Romanov EM. Growing seedlings of woody plants: bioecological and agrotechnological aspects. Yoshkar-Ola. 2000.

6. Sokolov AI, Pekkoev AN, Kharitonov VA, Krivenko TI. Uskorennoe vyrashchivanie kul'tur eli v srednetaezhnoy podzone Karelii [Fast Growing of Spruce Crops in the Middle Taiga Subzone of Karelia]. Lesnoy zhurnal. 2013;(5):96-105.

7. Khlyustov VK, Zavarzin VV. The role of fullness and density in the natural formation of stands. Bulletin of Moscow State Forest University - Forest Bulletin. 2015;6(19):12-16.

8. Bryntsev VA, Kozhenkova AA. Forest seed production. Moscow. 2001.

9. Lyubavskaya AYa. Forest breeding and genetics. Moscow. 1982.

10. Bobushkina SV. The intensity of growth and development of pine seedlings with a closed root system under different growing conditions for reforestation in the Arkhangelsk region. Arkhangelsk. 2014.

11. Gavrilova OI. Reforestation of clearcuts and productivity of coniferous forest crops of the Republic of Karelia. Arkhangelsk. 2012.

12. Sokolov AI. Ecological and silvicultural basics of creating forest crops on unforested felling with littered soils of the North-West of the taiga zone. Arkhangelsk. 2012.

13. Asmolovsky MK. The state and prospects of mechanization of planting of forest crops. Transactions of BSTU, no 1. Forestry. 2015;1(174):119-123.

14. Bartenev IM, Yudin RV. Scientific research in the field of advanced technologies and mechanization of work in the forest complex. Voronezh. 2019.

15. Dornyak OR, Drapalyuk MV, Kazakov IV, Orudzhov, ES. A mathematical model of the stress-strain state of the soil in the process of its interaction with the working bodies of the digging machine. Forestry Journal. 2019;2(34):157-163

16. Druchinin DYu, Drapalyuk MV. The use of large-sized planting material in the creation and reconstruction of protective fores stands. News of the St. Petersburg Forestry Academy. 2018;223:174-186

17. Popikov PI. Hydraulic Drive Forestry Machinery Workflows. Voronezh. 2001.

18. Sungurova NR. Theory and practice of artificial reforestation in the north of the Russian Plain. Arkhangelsk. 2018.

19. Titov PI. Improving the technological process and the design of a forest planting machine for nurseries. Voronezh. 2006.

20. Shavkov MV. Justification of the parameters of a combined opener of a forest planting machine.Voronezh. 2013.

21. Vinokurov VN, Silaev GV, Zolotarevsky AA. Machines and mechanisms of forestry and landscape gardening. Moscow. 2004.

22. Vasilev AS, Shegelman IR, Aminov VN, Kameneva EE, Shchukin PO. Philosophy of technical equipment improvement as exemplified by a jaw crusher. Indian Journal of Science and Technology. 2016;9(46):107536-

23. Shegelman IR, Shtykov AS, Vasilev AS, Galaktionov ON, Kuznetsov AV, Sukhanov YV. Systematic Patent-Information Search as a Basis for Synthesis of New Objects of Intellectual Property: Methodology and Findings. International Journal of innovative Technology and Exploring Engineering (IJITEE). 2019;8(8):395-403.

24. Posmetiev VI. Fundamentals of improving the protection of forest tillage implements from overloads. Voronezh. 2001.

25. Bartenev IM, Popov IV. Patent of the RF No. 2546163. Machine for planting seedlings with a closed root system. VSFEA. 2015.

26. Bartenev IM. Patent of the RF No. 2535400. Forest planting machine. VSFEA. 2014.

27. Bartenev IM, Bychkov AA. Patent of the RF No. 255009 Machine for planting seedlings with a closed root system. VSFEA. 2015

28. Dubenok NN, Semenenko SYa, Abezin VG. Patent of the RF No. 2684316. A machine for planting seedlings of forest and garden cults. FSC AILKPA. 2019

29. Pokrovskaya AA. Patent of the RF No. 2584616. Close-up working body of a forest planting machine. Pacific State University. 2016.

30. Martynyuk AA, Kazakov VP, Prokazin NE. Patent of the RF No. 169357. Machine for planting seedlings with a closed root system. ARRIFFM. 2017

31. Martynyuk AA, Kazakov VP, Prokazin NE. Patent of the RF No. 177604. Forest planting machine for seedlings with a closed root system. ARRIFFM. 2018.

32. Zhdanov YuM, Lubrinets VL. Patent of the RF No. 153681 Forest planting machine. ARSRAI. 2015.

33. Romanov EM, Mukhortov DI, Lezhnin KT. Patent of the RF No. 174663. Landing apparatus of forest planting machines. CIE "Novator". 2017.

34. Novikov AI. Patent of the RF No. 2714705. Method of forest restoration. VSFEA. 2020.

35. Tsarev EM, Kalashnikova TS, Pyrkina OYu, Tatarinov DS Patent of the RF No. 2572316. A manual device for forming holes for planting containerized seedlings. VSU. 2016.

36. Tsarev EM, Tatarinov DS, Anisimov SE. Patent of the RF No. 2673743. A manual device for the formation of holes for planting containerized seedlings. VSU. 2018.

37. Romanov EM, Kirillov SV, Krasnov VG. Patent of the RF No. 2679680. Trailer device for the formation of landing holes with a fixed pitch. VSU. 2019.

38. Pashkovsky PP, Ivanov YuV, Kartashov AV. Patent of the RF No. 2548190. Method for growing seedlings of Scots pine (Pinussylvesrtis L.). Institute of Plant Physiology K.A. Timiryazev. 2015.

39. Voronin AA, Lepeshkina LA, Klevtsova MA. Patent of the RF No. 2663062. The method of presowing treatment of seeds of 
rare and relict plants by deep freezing. Voronezh State University. 2018

40. Kazakova EG. Patent of the RF No. 2683543, Method for presowing treatment of larch seeds to accelerate and increase the percentage of germination. LLC "Siledia". 2019.

41. Egorova AV, Chernobrovkina NP, Robonen EV. Patent of the RF No. 2662999. A method of obtaining a growth stimulator of pine ordinary. KSCRAS. 2018.

42. Drapalyuk MV, Platonov AA, Snyatkov EV, Platonova, MA. Patent of the RF No. 129753. Root trimmer. VSFEA. 2013.

43. Druchinin DYu, Drapalyuk MV, Pozdnyakov EV. Patent of the RF No. 190892. Root-cutter. VSFEA. 2019.

44. Rodin SA, Degtev VT, Kazakov VI. Patent of the RF No. 2646884. A method of trimming the roots of growing seedlings and a device for its implementation. ARRIFFM. 2018.

45. Gizatullin VN. Patent of the RF No. 154976. A hand tool for planting seedlings and saplings with the closed root system "Sabinsky Sword". Training and experimental Sabinsky forestry. 2015.

46. Romanov EM, Kirillov SV, Krasnov VG. Patent of the RF No. 2663594. Device for the formation of planting holes with a fixed step of landing. VSU. 2018.

47. Druchinin DYu, Drapalyuk MV, Milyaev AS. Patent of the RF No. 155474. Machine for digging seedlings with a lump of soil. VSFEA. 2015.

48. Brosalin VG, Goncharov AS, Zavrazhnov AA. Patent of the RF No. 194500. Machine for digging seedlings. MSAU. 2019.

49. Rodin AA, Rodin SA, Kalashnikova EA. Patent of the RF No. 2568750. The method of planting coniferous seedlings in the zone of radioactive contamination. MSFU. 2015.

50. Kazakov NV, Bogachev AP, Sadetdinov MA. Patent of the RF No. 2546898. Machine for forest use. Pacific State University. 2015.

51. Tsypuk AM, Egipti AE, Rodionov AV. Patent of the RF No. 176212. Machine for forming holes for planting plants in the ground. PetrSU. 2018.

52. Malyukov SV, Aksenov AA, Rubanov VN. Patent of the RF No. 181473. Machine for preparing seats. VSFEA. 2018.

53. Shastin VI, Polyushkin YuV. Patent of the RF No. 2643245. Reforestation method on mountain slopes. Irkutsk State Transport Service. 2018.

54. Shadrin AA, Shadrina SA. Patent of the RF No. 2184437. Forest planting machine for planting seedlings and seedlings in clearings. 2002.

55. Shegelman IR, Galaktionov ON, Vasiliev AS. Patent of the RF No. 2560187. A method of planting planting material with a closed root system of a forestry machine. PetrSU. 2015.

56. Keskilokhno AK. Patent of Russia No. 1616506. Device for planting plants. Company "Lannen tehtaat Oy" (Fi). 1985.

57. Shegelman IR, Galaktionov ON, Lukashevich VM. Patent of the RF No. 169676. Manual device for planting plants. PetrSU. 2017. 